junior technical schools and technical colleges. By many critics these proposals have been denounced, the grammar school as lopsidedly bookish, and the technical school as unlikely to engender that interest in the humanities which is one of the hall-marks of the well-educated man, and without which science cannot adequately express itself.

But the chief anxiety of some of the most experienced critics has been about the proposed modern schools, which must be the schools of the masses. It is perfectly true that the intention is to bring these schools up to the standard of the grammar schools in point of buildings, equipment, staff, size of classes, 'amenities', and so on. But just as the existing secondary schools inherited the traditions of the old grammar schools, so these senior or modern schools will inherit the traditions of the old elementary schools, into the details of which we need not enter. The staunch adherents of the democratic ideal must now, and for years to come, insist upon the fair promises embodied in the Bill being faithfully carried out, and they may have a hard struggle. The Bill does not lay down a three-fold division of the new secondary system, but leaves the local authorities to propose their plans of development. In other words, the Bill leaves room for experiment, even in the direction of the multilateral organization of American high schools. It is to be hoped that this ordered freedom to experiment will be benevolently regarded by the Minister, and will lead to valuable results. The general ends in view would be furthered if it could be arranged that a teacher's remuneration should depend upon his qualifications and experience, and not upon the kind of school in which he teaches. It would be a happy day for British education if some of the ablest and most enterprising members of the teaching profession could feel quite free to teach in any kind of school, without forfeiting one jot or tittle of their professional rights and privileges.

\section{SCIENTIFIC PERSONNEL IN INDUSTRY}

$\mathbf{N}^{\circ}$ one who has followed the recent discussions and reports on industrial and scientific research can have failed to notice the emphasis which has been placed on the research worker himself, and on the importance of ensuring that the conditions of service are such as to attract men of the highest ability and to retain their keenness and loyalty.

There is no more welcome passage in the report* of the Industrial Research Committee of the Federation of British Industries on "Industry and Research" than that which deals with the scientific worker in industry. It is clearly recognized that on the proper position of the research worker within the organization employing him depends to some extent the power of industry to attract the best scientific brains to its service. Nevertheless, the report finds it necessary to point out that the best results can only be obtained when the research staff is taken fully

* Federation of British Industries. Industry and Research : Report of the F.B.I. Industrial Research Committee. Pp. 24 . (London: Federation of British Industries.) into the confidence of the management and given a definite standing in the hierarchy of the organization. The research worker cannot be expected to perform his duties efficiently unless he has at his disposal all relevant information which is in the possession of the organization of which he is a member.

The report goes on to acknowledge that publication of the scientific aspects of his work is a legitimate ambition of every scientific worker, and that such ambitions are not as a rule inconsistent with the interests of firms engaged in competitive industry ; on the contrary, such publication increases the prestige of the firm concerned. Again, research and development can generally only be efficient on the basis of co-ordinated team-work, with a team properly balanced as between the leader and his various grades of assistants. The personality of the leader is of the greatest importance; a successful leader is one who appreciates the ambitions and capabilities of the separate members of his team and has the gift of communicating to them his own enthusiasm and a full appreciation of the objects the team is seeking to achieve; above all, he must be able to make discriminating acknowledgment of the contribution of each member of the team to the common objective. Sir Lawrence Bragg also has emphasized the need for more inspired leaders in industrial research, and suggested that we should divert more of the national genius to industrial research by recruiting potential leaders of this kind into industry, where they should be coached for positions of high responsibility. In his view the Central (Scientific and Technical) Register could be used to locate and recruit such men.

It may be encouraging to find such statements in the report of the Federation of British Industries, but neither here nor in the comments on the benefit that has flowed from the transfer of research workers having the requisite personal qualifications to commercial, administrative and other branches of activity is there the note of conviction that makes them something more than platitudes. The more an organization is staffed on all its sides by persons having an appreciation of science and research, the more progressive and adaptable to changing circumstances it is likely to be. Little benefit indeed will be derived from increasing the numbers of those engaged on research if trained minds are not more fully employed in other branches of industry, and the general scientific outlook of industry must be raised if the understanding and application of scientific inventions, discoveries and developments by industrial firms are to be increased.

We miss in the report the urgent sense of the primary importance of seeing that scientific workers of the highest quality are first attracted to industry and then set to work under conditions which give the utmost play and stimulus to their creative powers. That consciousness clearly inspired the motion tabled in November in the House of Commons by a large number of members of all parties, asking for wider State support in planning future developments for research, teaching and higher learning as a whole, including provision for a far greater number of persons highly trained in science and technology. Again, the 
report appears to ignore all those fundamental questions of the organization of research in relation to the personal factor which are vital and which were discussed by Dr. Alan Gregg, director for the medical sciences at the Rockefeller Foundation, in his Terry Lectures, "The Furtherance of Medical Research". Standards of remuneration must indeed be high enough to attract and to hold men of outstanding ability. They should also be such as to ensure that preoccupation with proper provision for their families does not intrude unduly on the research worker. Lord Bledisloe has rightly stressed the importance of mental concentration, quietude of mind and freedom from domestic anxieties if the research worker is to give of his best.

While, however, certain minimum standards are essential, the vital factor is the maintenance of the highest possible professional standards, the clash of mind with mind especially on the borderlands of sciences, the correction by every possible means of the ingrained evils of specialization. Refresher courses may do something to help, as may the transfer of staff within and without industry, for Lord McGowan was profoundly right in urging that scientific workers should not allow the lavish provision of scientific literature in the industrial library serving the research department of a large firm to lead them to refrain from joining professional societies and attending scientific meetings and participating in the discussions. The warning is timely and is a reminder of one respect at least in which the maintenance of the highest standards of research is a matter for the scientific worker himself.

A more generous policy in publishing the results of industrial research, as advocated by Lord McGowan and Dr. P. Dunsheath, and by Mr. Samuel Courtauld in a recent article in The Times, would undoubtedly have a vitalizing effect in this respect, and its indirect consequences in stimulating discussion and professional association might be out of all proportion to the direct value of interchange of information to which Lord McGowan referred, in such matters as fuel economy, heat transfer, corrosion and the design and performance of plant. Moreover, the question of the suitability of the present patent law system of Great Britain in this respect has been raised too often for it to be dismissed quite so cursorily as it was by Lord McGowan. It was raised most explicitly by Dr. Dunsheath, and Mr. Courtauld returns to the point when he urges that it is open to question whether the Government should assist research by direct contribution, or by remitting taxation, while allowing the fruits of that research to be withheld from the nation by means of patents not fully and efficiently worked.

On the other hand, as Mr. Courtauld recognizes, publication has its own difficulties. Governmentmaintained institutions must have a free hand, and fundamental research will be one of their main functions. The publication of fundamental discoveries must be subjected to the decision of a very high and impartial tribunal, always with an eye on possible foreign competitors. Existing interests must not be allowed to retard publication beyond the point where these coincide with public policy.
Mr. Courtauld is here entering on the difficult question of social adjustment. It may indeed be right and for the advantage of the community that a particular industry should be closed down, because of other benefits arising from the discovery or invention responsible. It may be questioned, however, whether this is relevant to the question of publication : if we make sure that such decisions affecting the fate of an industry are not determined by private interests but by public policy, which takes account of the displacements and adjustments involved, there seems to be no intrinsic reason for barring publication. Moreover, Mr. Courtauld's remarks in this connexion appear to threaten that full and free interchange of fundamental knowledge across national frontiers which is essential to scientific advance and the defence of which is one main concern of men of science in the present War.

Mr. Courtauld's challenge to the old-fashioned love of secrecy is, however, unmistakable, and many will hold with him that it has brought more harm than good to the manufacturer. Undoubtedly it undermines the relations between the research staff and management and hinders the establishment of that full confidence and understanding which play so important a part in stimulating research and bringing its conduct to the highest efficiency. The more liberal policy pursued in the United States may well be an important factor in some of the industrial achievements in that country. Mr. Courtauld is unquestionably right in holding that the maximum degree of publication and co-operation consistent with reasonable safeguards against abuse will accelerate the healthy growth of every industry based upon applied science.

It is clear, therefore, that the reports to which we have referred are far from exhausting this question of establishing the conditions under which research can be carried on with the greatest advantage. Fundamentally, we still know relatively little of the biology of invention or discovery, but in the organization and maintenance of research we are often very far from applying all the knowledge at our disposal, and these reports afford welcome evidence that this is realized and that further attempts are being made in this direction. Moreover, they indicate that industry is coming to understand that more could be done even before the scientific man enters the service of industry; the greater interest being taken by industry in technical education, and the recommendations for the more general provision of funds for the creation of fellowships, bursaries or the like at universities and technical schools and colleges for junior personnel in the industry who show an aptitude for a scientific career, are encouraging signs.

How great is the need in this respect is shown in an interim report of the British Association Com. mittee on Post-war University Education dealing with university entrance scholarships in England and Wales*. It is not merely that the supply of scholar-

* British Association. Committee on Post-War University Education. Report on University Entrance Scholarships in England and Wales. Pp. 8. (Iondon: Burlington House, 1943.) $6 d$. 
ships is inadequate, and that in particular if adult education becomes much more widespread there should be an increase in the number of university entrance scholarships offered without an upper age limit; the methods of selection themselves receive severe criticism. The Committee holds that the present system harms a large majority of the scholarship candidates, subjecting them to conditions which place a premium on absorptive processes; it ruins altogether a small percentage of the candidates and misses some first-rate material.

The attention which industry is already giving to qualities other than purely intellectual attainments in selecting its recruits should lead it to mark very carefully what this report says about the deleterious effect of the present scholarship system upon the social life of the school, and particularly the untoward effects, on boys much more worth while than many of the successful candidates, of concentrating undue attention upon the more brilliant minority. The Committee gives a strong warning as to the necessity of carrying selection a step further. If we are to make the best of our youth, we need to get into our universities more of the leaders of the coming generation as well as the intellectual elite. We need, besides scholars of outstanding intellectual quality, men and women who combine good intelligence with qualities of character and personality, so as to be the natural leaders in other fields than those of science and learning.

This plea for character and leadership is one to which assuredly industry should not turn a deaf ear. The plea that the assessment of deep scholarship should always be accompanied by the assessment of character, and that the latter for most assisted students should carry equal weight in considering their worthiness to be admitted to a university, has strong claims on the support of industry, which is already beginning to assess its recruits by some such standards. Industry could indeed, if it chose, lend powerful support in overcoming the obstacles to the appropriate remodelling of the scholarship examinations involved in the success of any such reform, and the experience of the interview it already possesses might well be drawn upon in establishing the more effective use of the interview, with the appropriate safeguards, in examinations for entrance scholarships to universities. With that, and with real weight attached to the candidate's school record, to his English essay and to his general papers as well as to his intellectual promise in his own special branch of study, we may well find such an improvement in the quality of the recruits industry draws from the universities as will react profoundly not only on the quality of industrial research and on the application of advances in science, but also on the whole standard of industrial leadership and management. What is essential is that industry should show even more of the spirit of co-operation and open-mindedness which these reports and papers display, and tackle with more determination and thoroughness those fundamental questions of the organization and the management of research over which the Federation of British Industries tends to pass too lightly.

\section{HISTORY OF ELEPHANTS}

\section{Proboscidea}

A Monograph on the Discovery, Evolution, Migration and Extinction of the Mastodonts and Elephants of the World. By Prof. Henry Fairfield Osborn. Edited by Mabel Rice Percy. (Published on the J. Pierpont Morgan Fund by the Trustees of the American Museum of Natural History.) Vol. 2 : Stegodontoidea, Elephantoidea. Pp. xxvii $+805-1176+19$ plates. (New York: American Museum Press, 1942.) 20 dollars.

THE Proboscidea are such very large animals that their fossil bones and teeth attracted attention in the far distant past, but only in 1698 did W. E. Tentzelius prove that giant bones found in a sandpit at Tonna in Thuringia were those of an elephant, and were not "minerale fossile, sed animale petrifactum". Before 1800 Blumenbach and Cuvier showed that some fossil elephant teeth belonged to species and genera no longer living.

Hugh Falconer, who died with much of his work unpublished in 1866, brilliantly ended another phase of the discovery and interpretation of fossil elephants by showing that they could be arranged in a morphological series providing every intermediate stage of tooth structure between a primitive mastodon and the most advanced true elephant, the mammoth. With the general acceptance of the theory of organic evolution, it was at once realized that Falconer's morphological series was in a wide sense an evolutionary one, but little real advance was made until, in 1904, C. W. Andrews found in Egypt two evolutionary stages earlier than any then known, which fitted into place before the beginning of Falconer's series ; and went on to give a convincing explanation of "how the elephant got his trunk".

Dr. Andrews was well aware that the series of forms he used was not a real phytogenetic series, that Moeritherium, its earliest term, was not actually the ancestor of its successor Palæomastodon, and similarly for the other stages. But he realized, for example, that Trilophodon angustidens was representative of all other Lower Miocene mastodons in its characteristic greatly elongated lower jaw, and that no form with the shortened, but still long, lower jaw of his next stage, Tetralophodon longirostris, had been found in rocks older than the Upper Miocene.

In his mind, the important fact was the time of first appearance of each stage of evolutionary advance, the trend of evolution being established on that basis without any attempt (which would then have been impossible) to sort out independent genetic lines among the whole material of fossil Proboscidea (cf. Phil. Trans., B, 196, 101).

In $1907, \mathrm{H}$. F. Osborn began to bring together in the American Museum of Natural History materials which would enable him to apply to Proboscidea those methods of analysis of structural details which he had already conceived and used in the study of Rhinoceroses and Titanotheres. In 1920, he began that detailed work, which continued until his death in 1935. At that time, 1,240 figures, each often containing many individual drawings or photographs, had been prepared for publication, much of the text was complete and some of it in type, and an immense accumulation of notes existed. The piety of Miss Mabel Rice Percy and others has enabled the whole to be published in two magnificent volumes, of which the first was reviewed in NATURE $(138,860)$ on its 